\title{
Growth of palladium nanoparticles on nanostructured highly ordered pyrolytic graphite
}

\author{
Z. Yuan, ${ }^{a}$ M.C. Hanf, ${ }^{\text {a }}$ R. Stephan, ${ }^{\text {a }}$ F. Dulot, ${ }^{a}$ E. Denys, ${ }^{\text {a }}$ A. Florentin, ${ }^{a}$ \\ W. Harbich ${ }^{\text {b }}$ and P. Wetzel ${ }^{\text {a* }}$
}

\begin{abstract}
We report on the growth of palladium nanoparticles on the basal plane of as-cleaved highly oriented pyrolytic graphite (HOPG) samples, and on $\mathrm{CO}_{2}$ ion sputtered nanostructured HOPG surfaces. The morphology of Pd nanostructures grown at room temperature is investigated by scanning tunneling microscopy (STM). The STM observations indicate that the morphology of the Pd films is strongly dependent on the HOPG surface. Stabilized Pd particles only form on the sputtered surface, while ramified Pd particles decorate the clean HOPG terraces. The prestructuring of HOPG surface leads to a selective location of particles at the rim of the nanopits generated by the $\mathrm{CO}_{2}$ ion sputtering and annealing of the surface. The correlation between size, form, density, spatial distribution of the Pd nanoparticles and the quantity of metal added on surface is discussed. We also describe trench channeling of graphite or graphene basal planes by means of Pd nanoparticles in an ambient environment. Copyright $\odot 2014$ John Wiley \& Sons, Ltd.
\end{abstract}

Keywords: nanoparticles; palladium; HOPG; STM

\section{Introduction}

Nanodimensional materials exhibit a variety of unusual chemical, physical and electronic properties. The high surfacearea-to-volume ratio and particle size confer on nanoparticles important chemical reactivity. Nanoparticles are thus very promising candidates for applications in catalysis. ${ }^{[1-6]}$ One can cite the more striking example of gold. Despite the fact that gold is inert on a macroscopic scale, gold becomes extremely reactive in the form of nanometric particles. ${ }^{[7]}$ It has been observed in particular the great effectiveness of the gold nanoparticles in the catalysis of the hydrochloration of acetylene and $\mathrm{CO}$ oxidation. ${ }^{[8]}$ Other transition metal nanoparticles (Pd, Pt or $\mathrm{Ni}$ ) are also interesting in particular for their catalytic, electric and magnetic properties. ${ }^{[9,10]}$

Among the transition metals, palladium is one of the most widely used as catalyst for a variety of reactions including hydrogenation, ${ }^{[11,12]}$ oxidation, ${ }^{[13,14]}$ carbon-carbon bond formation ${ }^{[15,16]}$ and electrochemical reactions in fuel cells. ${ }^{[17]}$ Moreover, $\mathrm{Pd}$ nanoparticles are promising candidates for applications such as hydrogen storage and sensors. ${ }^{[18]}$

However, the growth of stable nanoparticles is required for exploitation of their properties, and this remains an area of active research. Hence, the support plays an important role in the growth and the morphology of the nanoparticles and consequently on their catalytic properties. For example, the adsorption of $\mathrm{CO}$ on $\mathrm{Pd}$ nanoparticles deposited on an alumina support is partially dissociative, but this is not the case if they are deposited on a continuous $\mathrm{Pd}$ surface. ${ }^{[19]}$ For the $\mathrm{Pd} / \mathrm{Al}_{2} \mathrm{O}_{3}$ system, one observes a reduction of the desorption energy of $\mathrm{CO}$ when the size of the nanoparticles decreases, contrary to the case of the $\mathrm{Pd} / \mathrm{MgO}$ system. ${ }^{[6,20]}$

In this work we focus on the initial growth of Pd particles on both freshly cleaved HOPG surfaces and on prestructured HOPG surfaces obtained by $\mathrm{CO}_{2}$ ion sputtering followed by annealing in air. The weak interaction between the Pd nanoparticles and the as-cleaved graphite surface leads to the growth of unstable ramified Pd structures. The sputtered surfaces present artificial defect sites which serve as preferential nucleation sites for stable $\mathrm{Pd}$ particles. Characterization of the particles such as size, shape and distribution has been performed by means of scanning tunneling microscopy (STM) measurements. Additionally, we have observed trench channeling of graphite layers thermally activated in air by Pd nanoparticles.

\section{Experimental procedure}

The HOPG samples were cleaved in conventional way with adhesive tape and then introduced in the vacuum preparation chamber. In order to modify the HOPG surface morphology, part of the samples were sputtered with 3-keV carbon dioxide ions $\left(\mathrm{CO}_{2}\right)$ in order to generate defects. The sputtered samples were subsequently removed from the vacuum and heated in air at $850 \mathrm{~K}$ for $8 \mathrm{~min}$ and then replaced in vacuum. This two-step process allows the fabrication of etched nanopits on the HOPG surface. This procedure was successfully used to produce nanometer-sized pits on HOPG samples by sputtering with $\mathrm{Ar}^{+}$and following oxidation. ${ }^{[21,22]}$ The HOPG surface preparation parameters, such as $\mathrm{CO}_{2}$ ion energy, oxidation

\footnotetext{
* Correspondence to: P. Wetzel, CNRS-UHA, IS2M UMR CNRS 7361-UHA, Mulhouse 68057, France.

E-mail:patrick.wetzel@uha.fr
}

a CNRS-UHA, IS2M UMR CNRS 7361-UHA, Mulhouse 68057, France

b EPFL, ICMP, Lausanne, Switzerland 
temperature and oxidation time, have been optimized in order to create the maximum of artificial defects on the HOPG surface.

The Pd nanoparticles were grown on the HOPG surface, by evaporating $\mathrm{Pd}$, at room temperature, from an effusion cell at a base pressure of $5 \times 10^{-10}$ mbar. The deposition rate $\left(\sim 0.02 \mathrm{ML} \cdot \mathrm{min}^{-1}\right)$ was calibrated with a quartz micro-balance. The thickness of the film is given in monolayers (ML), where one $\mathrm{ML}$ corresponds to the atomic density of the HOPG(0001) surface, i.e. $3.85 \times 10^{15}$ atoms $/ \mathrm{cm}^{2}$.

An STM Omicron microscope, operating at room temperature, was used for the surface analysis. The surface morphology was imaged under constant-current mode using W-tips.

Analysis of the STM images has been carried out by using the software WSxM. ${ }^{[23]}$ The particle sizes given in this paper are apparent sizes. They appear larger as in reality because of tip convolution.

\section{Results and discussion}

\section{Pd nanoparticles on as-cleaved HOPG surfaces}

Figure 1 displays STM images of the nanoparticles morphology evolution for a Pd deposit of $0.5 \mathrm{ML}$ on an as-cleaved HOPG surface. The different images have been recorded successively.

Figure $1 \mathrm{~A}$ shows fuzzy $\mathrm{Pd}$ islands indicating particle mobility during the time needed to acquire the image. The parallel lines observed along the vertical direction, in the images of Fig. $1 \mathrm{~A}$ and $1 \mathrm{C}$,

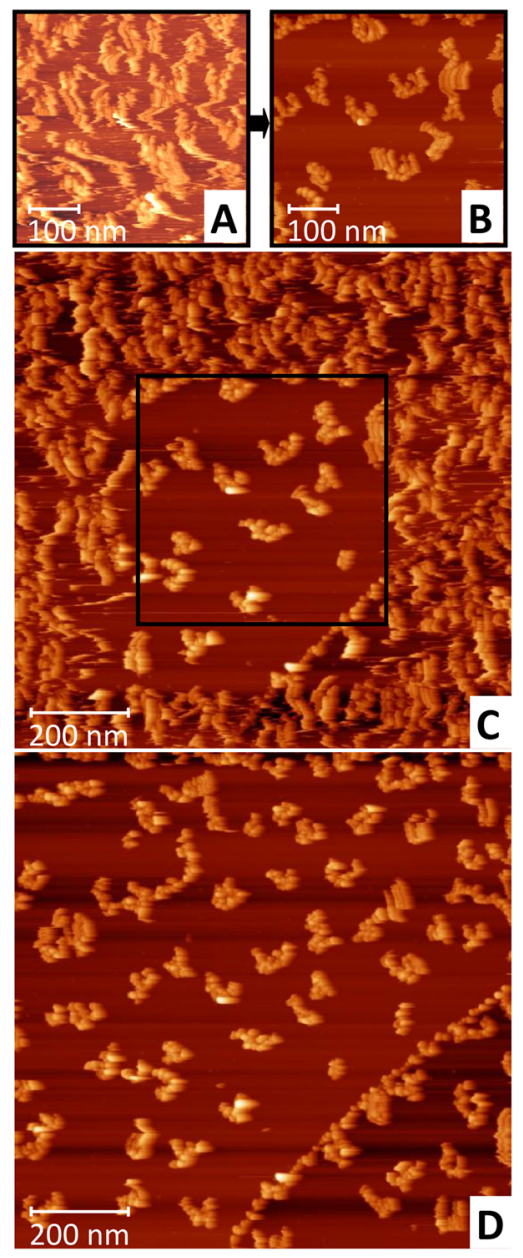

Figure 1. Filled state STM images of $0.5 \mathrm{ML}$ of $\mathrm{Pd}$ deposited on an ascleaved HOPG surface. Images A, B, C and D have been taken successively. (A-B) $500 \times 500 \mathrm{~nm}^{2}$; (C-D) $1000 \times 1000 \mathrm{~nm}^{2}, \mathrm{U}=-1.61 \mathrm{~V}, \mathrm{I}=0.5 \mathrm{nA}$. are the result of particles movement along this direction. This can be caused by dragging and pushing of the particles by the tip. After a second tip scan of the same area (Fig. 1B) the particles remain stable, and their shapes are more regular. One observes large-sized ramified islands located on the HOPG terraces. Each branch of the ramified islands is composed by the juxtaposition of individual nanoparticles, that is, the particles have formed branched structures rather than aggregating into compact islands. This behavior indicates that nanoparticles are displaced by the tip from their original position. Indeed the particle interaction with the HOPG surface characterized by $s p_{2}$ bonded carbon atoms is weak. Figure $1 \mathrm{C}$ shows a large-scale image where the center of the image matches the previously scanned area. We note that the islands in the center of the image did not move and that their shape and density are unchanged in this area, while the structures located around this zone appear quite unstable. Moreover, around the central area we observe movement of particles as in Fig. 1A. By repeating this operation one finds the same result (Fig. 1D). Note that Fig. 1C also shows the presence of a step edge saturated with Pd nanoparticles. The decoration of the step edge is unchanged after a second tip scan (Fig. 1D) indicating that the particles anchored at the step edge are very stable. For Pd coverages lower than $0.2 \mathrm{ML}$ only step edges and natural defects present on the terraces are decorated with Pd particles. ${ }^{[24]}$

Finally, it seems that the Pd islands located on a terrace remain motionless after two successive scans with the STM tip. This suggests that $\mathrm{Pd}$ atoms or particles are moved on the surface by the scanning tip and aggregate to form larger blocks which become stable because of their large size.

In light of the results presented in Fig. 1, because of the weak interaction between the HOPG support and the nanoparticles, we can assume that Pd particles deposited onto freshly cleaved HOPG would be submitted to sintering when exposed to elevated temperatures, or to reactant gases used for applications in catalysis. As a result, the catalytic activity of the nanoparticules would be lowered.

In conclusion, if one wants to manufacture HOPG surfaces with high densities of stable particles, it is necessary to anchor the particles through artificial defects created on the HOPG terraces.

\section{Pd nanoparticles on prestructured HOPG surfaces}

In this section we follow the evolution of Pd nanoparticles grown on nanostructured HOPG surfaces. The latter present nanopits with dangling bonds acting as nucleation centers for Pd nanoparticles.

Figure 2 shows a typical STM image of a HOPG surface after $\mathrm{CO}_{2}$ ion sputtering and oxidative etching. Many etched pits, with a nonuniform diameter distribution, have been produced on the surface. Most of the pits are circular in shape, but we can also see hexagonal shaped pits. It should be noted that for longer oxidation times the initial hexagonal-shaped pits are converted to round-shaped pits. The small pits, with a diameter around $8 \mathrm{~nm}$, are one or two monolayer deep, while pits of larger diameters (around $20 \mathrm{~nm}$ ) have depths greater than three monolayers. The pit density is approximately 770 per $\mu \mathrm{m}^{2}$. Note that the density of natural defects on HOPG surface is quite low $\left(1-5 \mu \mathrm{m}^{-2}\right)$.

Figure 3 presents STM images of Pd overlayers, grown on the prestructured HOPG surface, with coverages ranging from 0.25 to 1.0 ML.

For a Pd coverage of $0.25 \mathrm{ML}$ (Fig. 3A), the majority of Pd particles grow on the pit rims, indicating clearly that the latter act as nucleation centers for Pd. Note that for a Pd amount lower than $0.25 \mathrm{ML}$ 


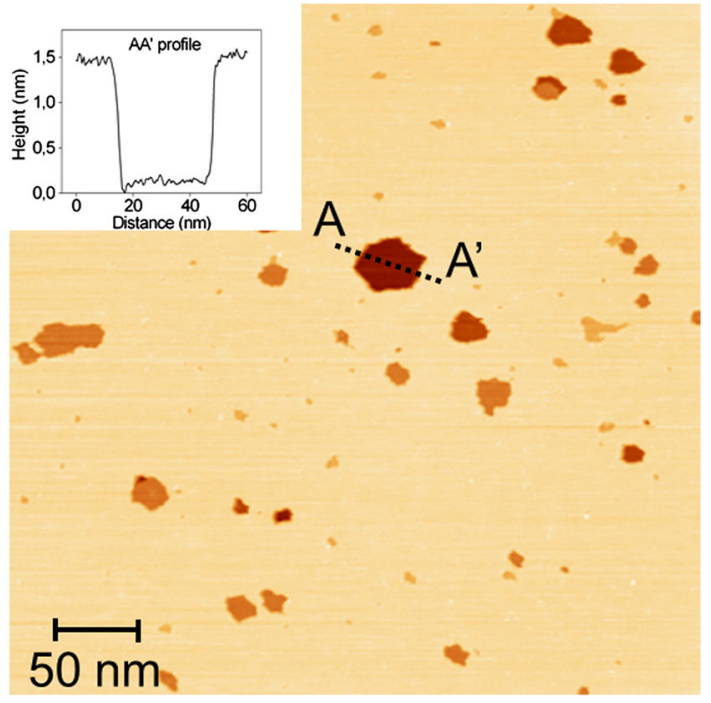

Figure 2. STM image $\left(400 \times 400 \mathrm{~nm}^{2}, \mathrm{U}=1.5 \mathrm{~V}, \mathrm{I}=0.5 \mathrm{nA}\right)$ of a prestructured HOPG surface obtained after $\mathrm{CO}_{2}$ ion sputtering $(3 \mathrm{keV})$ and heating in air at $850 \mathrm{~K}$ for $8 \mathrm{~min}$. The inset shows the depth profile along the $A A^{\prime}$ line. (inset of Fig. 3A), the Pd particles do not occupy the entire pit edges, while at $0.25 \mathrm{ML}$, the $\mathrm{Pd}$ particles decorate the total pit periphery forming dense collars. In addition, there are isolated Pd particles (see Fig. 4A) appearing to have nucleated on terraces. These isolated particles grow on small diameter craters (lower than $5 \mathrm{~nm}$ ); as a result, the latter are entirely recovered by $\mathrm{Pd}^{[25]}$

By further increasing the Pd amount (0.5-1.0 ML), particles grow randomly on terraces (Fig. $3 \mathrm{~B}-\mathrm{C}$ ). They tend to stick together forming chains which are anchored to collar particles, and probably to isolated particles. Horizontal bright streaks visible on the image (Fig. 3B) indicate that the Pd nanoparticles grown on terraces are not stable. For $1 \mathrm{ML}$ Pd the HOPG surface is fully covered by branched islands, and there are Pd particles growing inside the pits.

Now let us study the particles shape as a function of Pd coverage. Figure $4 \mathrm{~A}$ presents an enlarged view of isolated nanoparticles on a terrace. Line profiles, indicated by black dashed lines in Fig. 4A, reveal that these isolated structures resemble truncated spheres. ${ }^{[26]}$ The contact angle measured on various nanoparticles corresponds to a value of about $60^{\circ}$.

Figure $4 \mathrm{~B}$ and $\mathrm{C}$ shows pits with different diameters after the deposition of $0.25 \mathrm{ML}$ of $\mathrm{Pd}$. The pits are completely saturated with $\mathrm{Pd}$
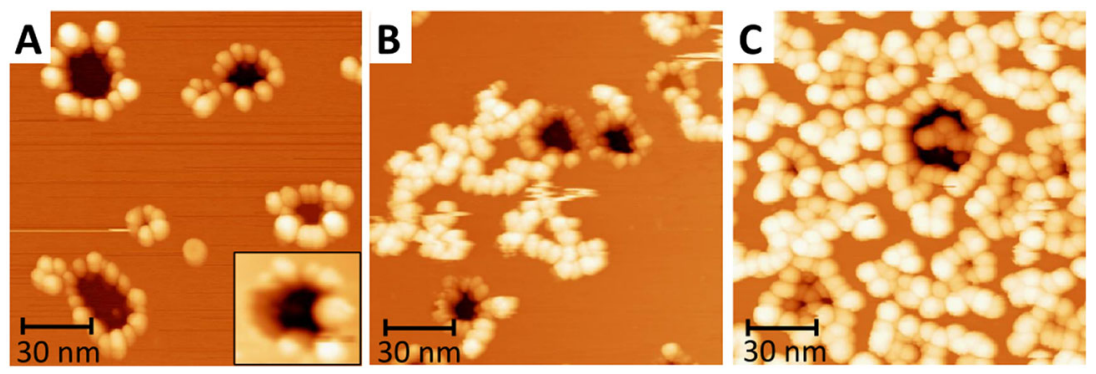

Figure 3. STM images of various Pd deposits at room temperature on prestructured HOPG. (A) $0.25 \mathrm{ML}\left(150 \times 150 \mathrm{~nm}{ }^{2}, I=0.1 \mathrm{nA}, \mathrm{U}=-0.5 \mathrm{~V}\right.$, inset: $0.15 \mathrm{ML}$ $\left(20 \times 19 \mathrm{~nm}^{2}, \mathrm{I}=0.1 \mathrm{nA}, \mathrm{U}=-0.5 \mathrm{~V}\right),(\mathrm{B}) 0.5 \mathrm{ML}\left(150 \times 150 \mathrm{~nm}^{2}, \mathrm{I}=0.1 \mathrm{nA}, \mathrm{U}=-0.95 \mathrm{~V}\right),(\mathrm{C}) 1 \mathrm{ML}\left(150 \times 150 \mathrm{~nm}^{2}, \mathrm{I}=0.1 \mathrm{nA}, \mathrm{U}=-0.87 \mathrm{~V}\right)$.
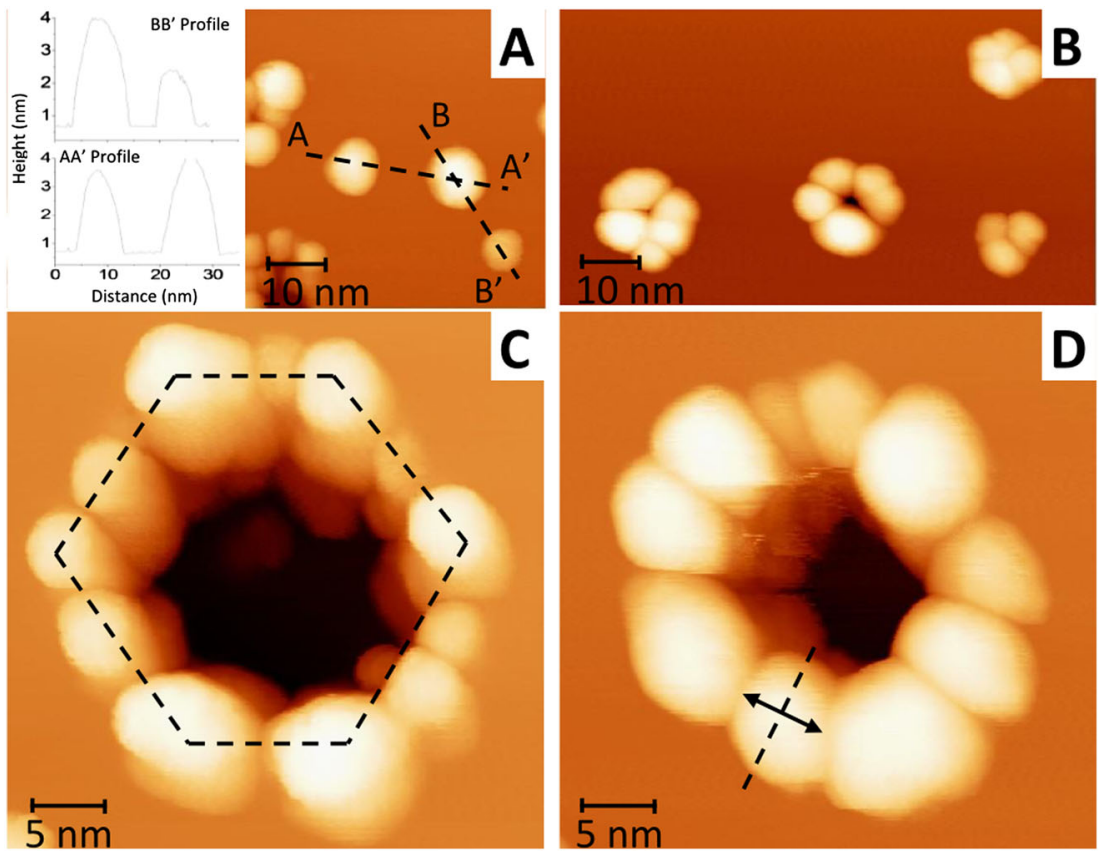

Figure 4. Enlarged STM views of Pd nanoparticles on prestructured HOPG: (A) $0.25 \mathrm{ML}$, isolated particles $\left(50 \times 50 \mathrm{~nm}^{2}, \mathrm{I}=0.5 \mathrm{nA}, \mathrm{U}=-0.5 \mathrm{~V}\right)$ and line profiles along straight lines $\mathrm{AA}^{\prime}$ and $\mathrm{BB}^{\prime}$; (B) $0.25 \mathrm{ML}$, particles around small pits $\left(90 \times 50 \mathrm{~nm}^{2}, \mathrm{I}=0.5 \mathrm{nA}, \mathrm{U}=-0.5 \mathrm{~V}\right)$; (C) $0.25 \mathrm{ML}$, particles of $\mathrm{Pd}$ around a hexagonal pit $\left(34.5 \times 34.5 \mathrm{~nm}^{2}, \mathrm{I}=0.5 \mathrm{nA}, \mathrm{U}=-0.5 \mathrm{~V}\right) ;(\mathrm{D}) 0.5 \mathrm{ML}$, particles of $\mathrm{Pd}$ around a hexagonal pit $\left(34.5 \times 34.5 \mathrm{~nm}^{2}, \mathrm{I}=0.5 \mathrm{nA}, \mathrm{U}=-0.5 \mathrm{~V}\right)$. 
particles. As can be seen also in Fig. 3A their number increases with the size of the pits. Figure $4 C$ shows a hexagonal pit decorated with $\mathrm{Pd}$ particles. The particles which are located at the corners are larger in size than those at the edges. This size difference indicates that $\mathrm{Pd}$ particle nucleation is highly dependent on the nature of the carbon sites on the HOPG, as for corner sites more carbon dangling bonds are available compared to carbon atoms at the edges. Thus, more $\mathrm{Pd}$ atoms will be trapped at the corners leading to larger particles.

Figure 4D shows that increasing the Pd coverage leads to an increase of the cluster size, without significant change of the cluster density. One observes a change in the particle form due to steric obstruction. Initially spherical, the clusters become slightly elliptic or trapezoidal. They grow laterally perpendicular to the circumference of the pits, towards the center and the outside of the pits.

In this respect, Fig. 5 shows the mean width distributions for $\mathrm{Pd}$ particles anchored on the periphery of the pits, as a function of $\mathrm{Pd}$ coverage. For the elongated particles, the width is measured at the middle of the particle (delineated by the black double arrow on Fig. 4D). Figure 5 reveals that the smallest particles obtained for 0.15 and $0.2 \mathrm{ML}$ of $\mathrm{Pd}$ have an average width of about $3.6 \mathrm{~nm}$. For $0.25 \mathrm{ML}$ of Pd the particles have a width of about $4.9 \mathrm{~nm}$. Larger particles with average width of about 5.4 and $6.4 \mathrm{~nm}$ are observed for 0.5 and $1 \mathrm{ML}$ deposits, respectively.

We would like to point out that, according to the STM images, neighboring particles within a collar do not coalesce to form a continuous Pd crown. However, it is necessary to take into account the convolution effects of the STM tip, which implies that the particles may not be really contiguous.

Figure 6 shows the evolution of the average heights of the particles as a function of the Pd coverage. One clearly notices that the particle height remains approximately constant for $\mathrm{Pd}$ deposits below $0.5 \mathrm{ML}$ and then significantly increases for higher Pd amounts. This observation is consistent with the particles width augmentation starting at a $0.5 \mathrm{ML} \mathrm{Pd}$ coverage, and may be related to the saturation of the pit rims with $\mathrm{Pd}$ nanoparticules.

\section{Thermal stability of metal particles}

If the particles are to be used as catalysts, their thermal stability is a major issue. We reported in a previous study on the temperature behavior of Pd particles under ultra-high vacuum conditions. ${ }^{[25]}$ Actually, our STM measurements did not reveal any apparent annealing influence on the surface morphology for temperatures up to $700 \mathrm{~K}$.

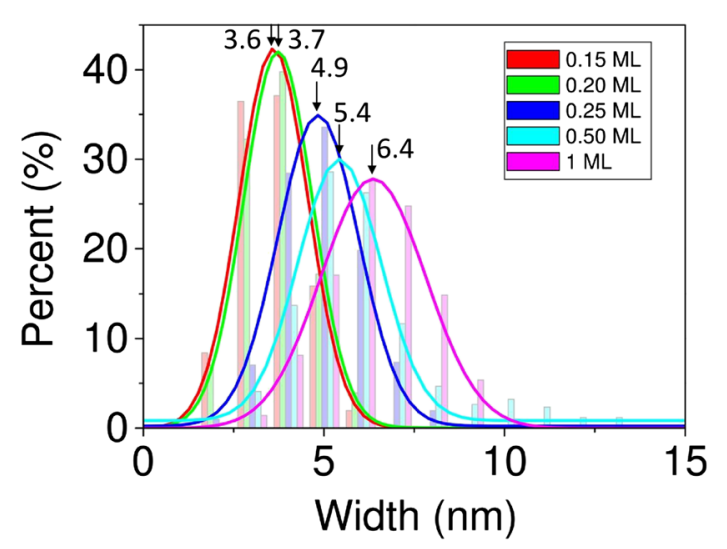

Figure 5. Histograms of the particles width distribution for various $\mathrm{Pd}$ coverages. The mean value is indicated for each distribution.

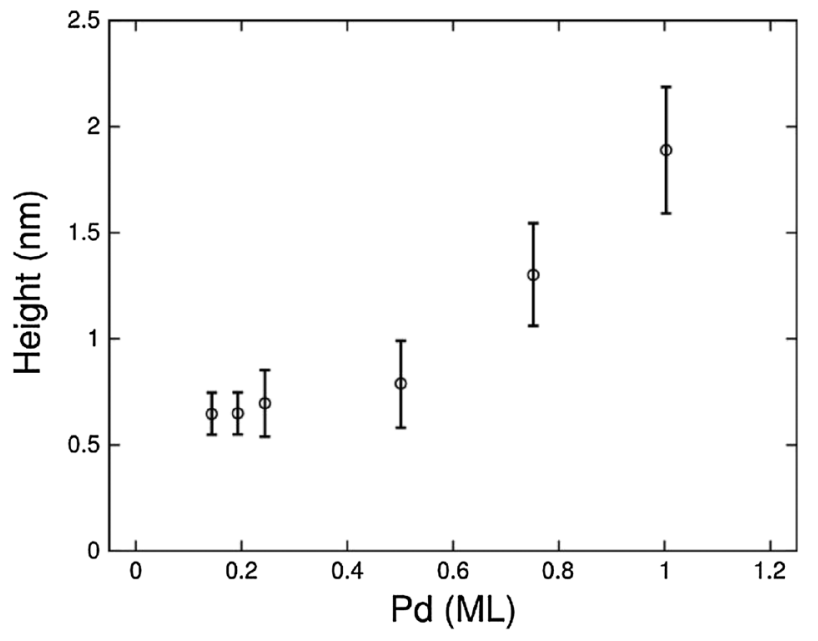

Figure 6. Mean particle height as a function of Pd coverage. Errors bars correspond to standard deviation values.

We are now interested in the evolution of the Pd particles when the system is annealed in air.

Figure 7 shows the surface morphology for $0.25 \mathrm{ML}$ of Pd deposited at room temperature onto a prestructured HOPG surface and heated in air at around $730 \mathrm{~K}$ for $10 \mathrm{~min}$. After annealing, the sample is transferred back to the STM chamber. This treatment drastically modifies the surface morphology.

First, the density of the Pd particles is significantly reduced, whereas their size increases significantly (average diameter $\sim 12 \mathrm{~nm}$ ). This means that a fraction of the Pd clusters grown in UHV is not stable in air at this temperature and that some $\mathrm{Pd}$ particles have been evaporated from the surface.

Second, etched trenches of different lengths, depths and widths are present starting from the circular or hexagonal craters of the prestructured HOPG surface. The majority of trenches have a worm-like shape. They are essentially formed by channeling of the catalytic Pd nanoparticles initially located at the rims of the craters. A single Pd nanoparticle is clearly observed at the etching front of some of the trenches, demonstrating that the etching process occurs with a displacement of the metal particle.

Although large wide trenches are oriented along various directions, some of them exhibiting a relatively narrow width are almost straight and follow one of the crystallographic directions of the

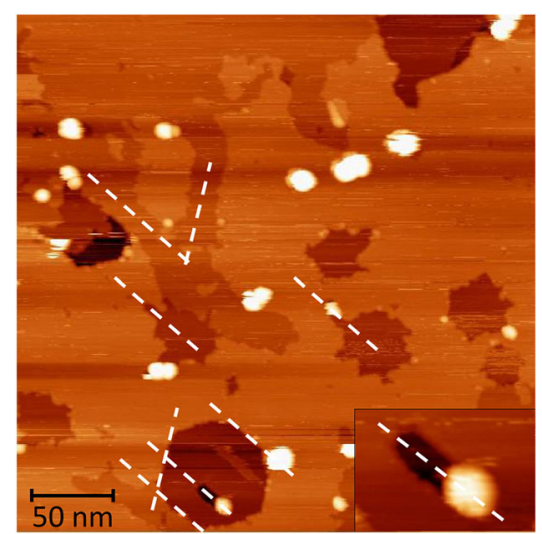

Figure 7. STM image of $0.25 \mathrm{ML}$ of Pd deposited at room temperature on a prestructured HOPG surface after annealing in air at around $730 \mathrm{~K}$ for $10 \mathrm{~min}$ $\left(300 \times 300 \mathrm{~nm}^{2}, \mathrm{U}=-1.5 \mathrm{~V}, \mathrm{I}=0.5 \mathrm{nA}\right)$. Inset $\left(50 \times 34 \mathrm{~nm}^{2}, \mathrm{U}=-1.5 \mathrm{~V}, \mathrm{I}=0.5 \mathrm{nA}\right)$. 
HOPG surface. The white dashed lines in Fig. 7 indicate crystalline directions of the substrate. The directions are identified with respect to the edge orientations of the hexagonal hole visible at the bottom of the Fig. 7. The inset of Fig. 7 shows an enlarged view of the hexagonal hole where a trench etched by a mobile Pd particle along a crystallographic direction of the HOPG basal plane is observed. As a result, the initial hexagonal-shaped pits are converted to star-shaped pits.

The trench formation is related to the oxidation of the HOPG surface, induced by the oxygen present in the air during annealing of the sample. We should emphasize that the surface of pure HOPG is inert under oxygen for temperatures lower than $800 \mathrm{~K}$. Thus, the Pd clusters act as catalysts for the oxidation of the graphite surface at lower temperature. A similar result was obtained by M. Hugentobler et al. ${ }^{[27]}$ They observed etching of HOPG graphene layers catalyzed by gold particles stabilized in nanosized pits. Other studies found that catalytically active metal ( $\mathrm{Ag}, \mathrm{Ni}$ and $\mathrm{Fe}$ ) nanoparticles located at the step edges of HOPG are able to etch graphite creating trenches across graphene layers. ${ }^{[28-30]}$

Two reaction mechanisms can be proposed to explain the observed catalytic oxidation of carbon by the $\mathrm{Pd}$ nanoparticles, through the carbon atoms dangling bonds available at the pits edges. Both are based on the adsorption and dissociation of molecular oxygen on the Pd nanoparticle, followed either by diffusion of atomic oxygen to the carbon edge and subsequent reaction to form $\mathrm{CO}$ and $\mathrm{CO}_{2},{ }^{[30,31]}$ or by migration of carbon resulting from the $\mathrm{Pd} / \mathrm{C}$ reaction at the interface and then formation of $\mathrm{CO}$ and $\mathrm{CO}_{2}{ }^{[29-33]}$

As mentioned previously, the measured STM particle sizes are apparent sizes. In particular, measurement of the lateral particle sizes is overestimated due to the limited lateral resolution of STM tips. According to the reaction mechanism for the catalytic oxidation by Pd particles, and thanks to the channel formation, we can suppose that the width of each channel is equal to the diameter of the particle which created it. As mentioned previously, Fig. 7 shows etched trenches with Pd particles located at the end of the trenches. Statistical measurements show that the relationship between the average diameter of particles and the average width of the channels is around 1.3, which leads to a more accurate measurement of the lateral particle size.

\section{Conclusion}

Pd nanoparticles were grown onto cleaved and nanostructured HOPG surfaces. The obtained nanoparticles were investigated with STM. On the cleaved HOPG surface the growth of unstable ramified islands is observed. On the nanostructured surface, pit edges are preferentially decorated with stable Pd nanoparticles forming collars. The Pd growth on prestructured HOPG is very interesting because it allows the growth of particles of relatively comparable sizes. Moreover, these metallic collars could show an enhancement of Raman scattering for molecules adsorbed on metallic surfaces and therefore may be efficient sensors for biomolecule detection.

Finally, formation of channels by catalytic reaction of HOPG by Pd nanoparticules was observed.

\section{Acknowledgements}

This work has been supported by the CNRS and C'Nano Grand Est foundation.

\section{References}

[1] J. D. Aiken III, R. G. Finke, Catal. J. Mol. Catal. A: Chem. 1999, 145, 1.

[2] A. Z. Moshfeg, J. Phys. D Appl. Phys. 2009, 42, 233001.

[3] I. V. Lebedeva, A. A. Knizhnik, A. M. Popov, B. V. Potapkin, J. Phys. Chem. C 2012, 116, 6572.

[4] D. Astruc, Inorg. Chem. 2007, 46, 1884.

[5] A. T. Bell, Science 2003, 299, 1688.

[6] G. Sitja, S. Le Moal, M. Marsault, G. Hamm, F. Leroy, C. R. Henry, Nano Lett. 2013, 13, 1977.

[7] M. Haruta, Catal. Today 1997, 36, 153.

[8] G. J. Hutchings, M. Haruta, Appl. Catal. Gen. 2005, 291, 2.

[9] U. Heiz, E. L. Bullock, J. Mater. Chem. 2004, 14, 564.

[10] S. Schweizer, J. M. Becht, C. Le Drian, Tetrahedron 2010, 66, 765.

[11] N. Semagina, A. Renken, L. Kiwi-Minsker, J. Phys.Chem. C 2007, 111, 13933.

[12] O. M. Wilson, M. R. Knecht, J. C. Garcia-Martinez, R. M. Crooks, J. Am. Chem. Soc. 2006, 128, 4510.

[13] N. Dimitratos, F. Porta, L. Prati, Appl. Catal. A: Gen. 2005, 291, 210.

[14] Z. Hou, N. Theyssen, A. Brinkmann, W. Leitner, Angew. Chem. Int. Ed. 2005, 44, 1346.

[15] M. Beller, H. Fischer, K. Kühlein, C. P. Reisinger, W. A. Herrmann, J. Organomet. Chem. 1996, 520, 257.

[16] R. Narayanan, M. A. El-Sayed, J. Catal. 2005, 234, 348.

[17] S. Cheong, J. D. Watt, R. D. Tilley, Nanoscale 2010, 2, 2045.

[18] J. Cookson, Platinum Met. Rev. 2012, 56, 83.

[19] H. Cordatos, T. Bunluesin, R. J. Gorte, Surf. Sci. 1995, 323, 219.

[20] C. R. Henry, C. Chapon, C. Goyhenex, R. Monot, Surf. Sci. 1992, 272, 283.

[21] J. R. Hahn, H. Kang, S. M. Lee, Y. H. Lee, J. Phys. Chem. B 1999, 103, 9944.

[22] H. Hövel, Appl. Phys. A: Mater. Sci. Process. 2001, 72, 295.

[23] I. Horcas, R. Fernandez, J. M. Jomez-Rodriguez, J. Colchero, J. Gomez-Herrero, A. M. Baro, Rev. Sci. Instrum. 2007, 78, 013705.

[24] S. Gibilisco, M. Di Vece, S. Palomba, G. Faraci, R. E. Palmer, J. Chem. Phys. 2006, 125, 84704

[25] Z. Yuan, R. Stephan, M. C. Hanf, J. M. Becht, C. Le Drian, M. Hugentobler, W. Harbich, P. Wetzel, Eur. Phys. J. D 2011, 63, 401.

[26] H. Hövel, I. Barke, Prog. Surf. Sci. 2006, 81, 53.

[27] M. Hugentobler, S. Bonanni, A. Sautier, W. Harbich, Eur. Phys. J. D. 2011, 63, 215.

[28] N. Severin, S. Kirstein, I. M. Sokolov, J. P. Rabe, Nano Lett. 2009, 9, 457.

[29] L. C. Campos, V. R. Manfrinato, J. D. Sanchez-Yamagishi, J. Kong, P. Jarillo-Herrero, Nano Lett. 2009, 9, 2600.

[30] S. S. Datta, D. R. Strachan, S. M. Khamis, A. T. C. Johnson, Nano Lett. 2008, 8, 1912.

[31] P. J. Goethel, R. T. Yang, J. Catalysis 1988, 111, 220.

[32] L. Ci, Z. Xu, L. Wang, W. Gao, F. Ding, K. Kelly, B. Yakobson, P. Ajayan, Nano Research 2008, 1, 116.

[33] F. Ding, P. Larsson, J. A. Larsson, R. Ahuja, H. Duan, A. Rosen, K. Bolton, Nano Lett. 2008, 8, 463. 